\title{
Perinatal Outcome of the Second Twin
}

\author{
Joshi R, Baral G \\ Department of Obstetrics and Gynaecology, Paropakar Maternity and Women's Hospital, Kathmandu
}

Received: March 05, 2014; Accepted: December 12, 2014

\begin{abstract}
Aims: The purpose of this study was to determine the perinatal outcome of the second twin compared to the first one.
Methods: This is a hospital based comparative study of 60 pregnant women with twin pregnancy at Paropakar Maternity and Women's Hospital, Kathmandu from 14 January 2013 to13 April 2013. Apgar score and admission to neonatal intensive care unit of the first and the second twins were studied in relation to the gestational age, chorionicity, mode of delivery, interdelivery interval and birth weight. Mc Nemars test was used with 0.05 as the level of significance.
\end{abstract}

Results: Among 60 sets of twins, Apgar score of the second twin was found to be lower than the first one ( $p=0.02)$ in general and in preterm gestation $(\mathrm{p}=0.049)$, dichorionic diamniotic chorionicity $(\mathrm{p}=0.012)$, vaginal delivery $(\mathrm{p}<0.001)$, inter-delivery interval of $<30$ minutes $(p=0.007)$ and birth weight discordance of $<30 \%(p=0.014)$. Admission to neonatal intensive care unit was not significant $(\mathrm{p}=0.5)$.

Conclusions: Second twin had low Apgar score and the neonatal admission rate was similar for both twins.

Keywords: Apgar score; chorionicity; twin pregnancy.

\section{INTRODUCTION}

Twin pregnancies have been found to vary in different parts of the world. The highest incidence is in Nigeria (49/1000) and the lowest in China and Japan (2/1000) while Europe and USA have the intermediate incidence $(5.9-8.9 / 1000) .{ }^{1}$ The incidence of twin pregnancy has been on the rising trend, $65 \%$ since 1980. ${ }^{2,3}$ There were 194 (1\%) twin pregnancies out of 19,247 total deliveries a year prior to the study at Paropakar Maternity and Women's Hospital in Kathmandu. ${ }^{4}$

This study was warranted due to the increased incidence of foetal malpresentation, preterm labour, birth weight discordance, placental abnormalities and operative deliveries in twin pregnancy. ${ }^{1}$ This study was an attempt to find out the outcome of the second twin in terms of the Apgar score at 5 minutes and the need for neonatal intensive care unit admission of the second twin in relation to the gestational age, chorionicity, mode of delivery, delivery interval between the first and the second twin and the birth weight.

\section{CORRESPONDENCE}

Dr Rijuta Joshi Jha

Department of Obstetrics and Gynaecology,

Paropakar Maternity and Women's Hospital, Kathmandu

Email: dr.rijutajoshijha@yahoo.com

Phone: +977-9851151830

\section{METHODS}

A comparative study of 60 twin pregnancies with non-probability sampling technique was done at Paropakar Maternity and Women's Hospital, Thapathali, Kathmandu, for three months from 14 January 2013 to 13 April 2013. All pregnant women with twin pregnancy of more than 28 weeks of gestation were included in the study. Intrauterine death of one foetus and gross congenital anomalies were excluded. Approval was taken from the institutional review committee of the hospital and written informed consent from the patient was taken. The data were entered in SPSS spread sheet (version 16). Mc Nemars test was used and p-value was considered significant at $<0.05$.

\section{RESULTS}

Total 60 sets of twin deliveries were analyzed. Most of the mothers $(88.3 \%, \mathrm{n}=53)$ were in between the age of 20-34 years and $41.6 \%(n=25)$ of them were nullipara followed by $35 \%(\mathrm{n}=21)$ being primipara. Almost equal frequency of the mothers $(51.7 \%$ and $48.3 \%$ respectively) had the delivery at the gestational age of $<37$ weeks and $\geq 37$ weeks. Majority of the pregnancy $(58.3 \%, \mathrm{n}=35)$ were dichorionic diamniotic (DCDA). Almost equal frequencies of the deliveries of both twins $(45 \%$ and $50 \%$ respectively) were done vaginally and by caesarean section. Majority $(91.7 \%, \mathrm{n}=55)$ of the cases had inter-delivery interval of $<30$ minutes. 


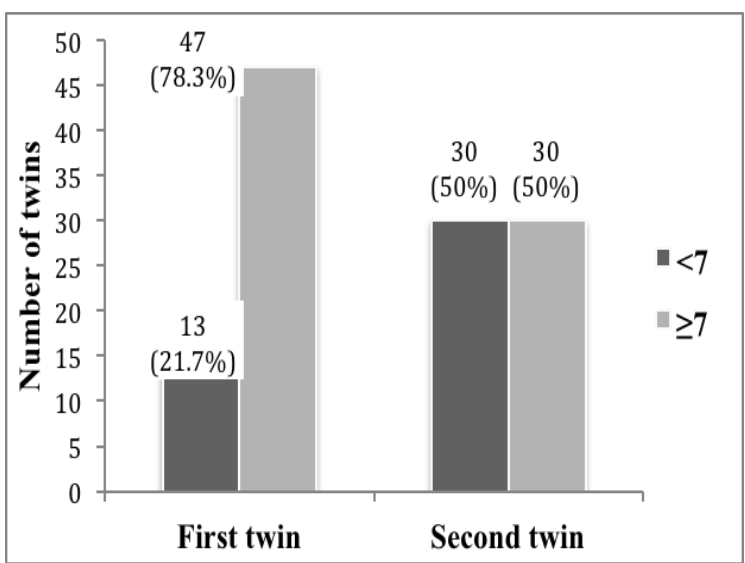

Figure 1. Apgar score of the first and the second twin.

Fifty percent $(n=30)$ of the second twins had Apgar score of $<7$ and only $21.7 \%(n=13)$ of the first twin had low Apgar score which was statistically significant $(p=0.006)$ as shown in Figure 1 , but only $30 \%(n=18)$ of the second twins and $25 \%(n=15)$ of the first twins required admission to neonatal intensive care unit, and was not statistically significant $(\mathrm{p}=0.508)$.

Twenty-five percent $(n=15)$ preterm and 25\% $(n=15)$ term second twins, and $10 \%(n=6)$ preterm and $11.7 \%$ $(n=7)$ term first twins had Apgar score less than 7.

Vaginal delivery shows significant effect $(\mathrm{p}<0.001)$ for low Apgar score (Figure 2A and 2B), but the neonatal intensive care unit admission rate was not different $(p=0.68)$.

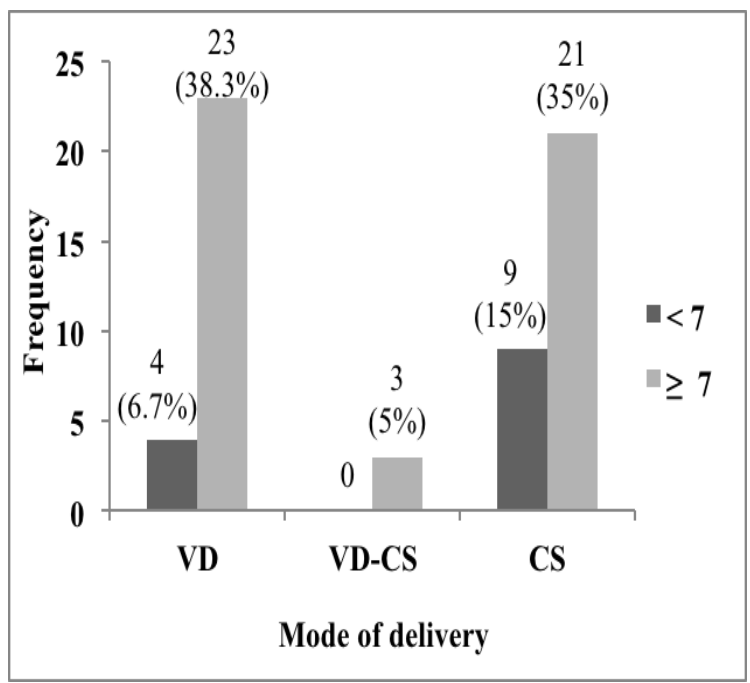

Figure 2A. Apgar score of the first twin in relation to the mode of delivery.

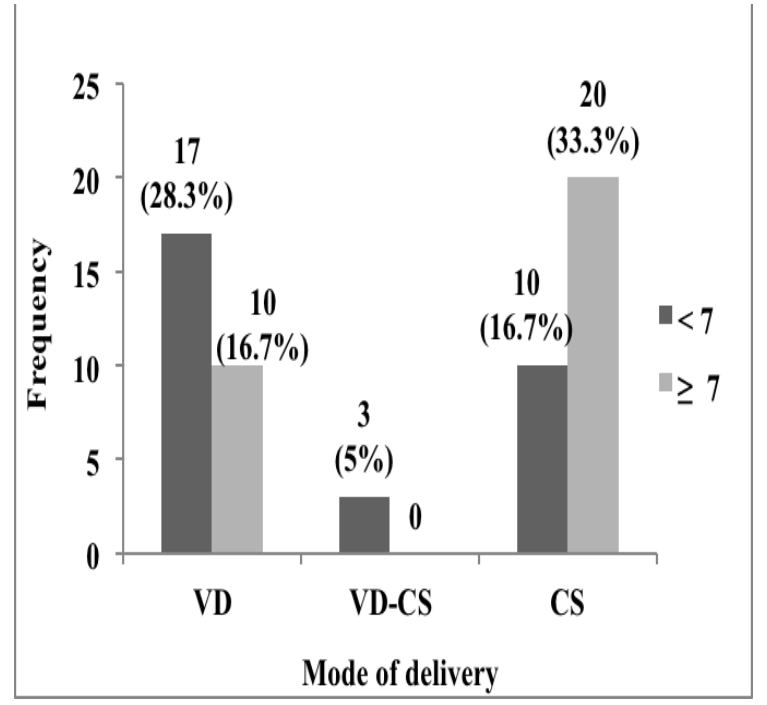

Figure 2B. Apgar score of the second twin in relation to the mode of delivery.

Most of the second twins $(91.7 \%, n=55)$ were delivered within 30 minutes. Apgar score of $<7$ in the second twin was found to be statistically significant $(p=0.007)$ with respect to the inter-delivery interval of $<30$ minutes but there was no difference in the neonatal admission rate $(\mathrm{p}=0.219)$.

There were $75 \%(n=90)$ low birth weight babies and only $34.4 \%(n=31)$ of them required admissions for neonatal care but, out of $25 \%(n=30)$ average weight babies, only two (one first twin and one second twin) were admitted. There was no difference in low Apgar score in either group $(\mathrm{p}=0.50)$.

Among the twins with birth weight discordance of $<30 \%$, equal number of babies were seen in two Apgar score group in the second twins and 71.7\% (43 vs. 13) of the first twins had good Apgar score of $\geq 7$ $(p=0.014)$ compared to the second twins. There was no statistical difference in neonatal intensive care unit admission rate $(\mathrm{p}=1)$.

Perinatal mortality was $28.3 \%(n=17)$ with $5 \%(n=3)$ stillbirths (second twins only) and $23.3 \%(n=14)$ early neonatal deaths (10 second twins and four first twins). Perinatal mortality was more on the second twins $(21.7 \%, \mathrm{n}=13)$. The causes of early neonatal death for the first twins were sepsis $(n=2)$, prematurity $(n=1)$ and respiratory distress syndrome $(n=1)$. In the second twins, the causes were sepsis $(n=4)$, perinatal asphyxia $(n=4)$, prematurity $(n=1)$ and respiratory distress syndrome $(n=1)$. 


\section{DISCUSSION}

Since the past three decades there has been tremendous increase in multiple gestation, which has not only created a public health concern but also a medical dilemma. ${ }^{2,3}$ Compared to the singleton pregnancies, in twin pregnancy there is much higher occurrence of almost all obstetric complications with much worse perinatal outcomes due to increasing morbidity and mortality. Even among the first born and the second born twin, the second born twin is in much disadvantage. This study was conducted to evaluate the difference in the perinatal outcome between them.

In this study, low Apgar score in the second twins was comparable to the similar study done by Hartley and Hitti, ${ }^{5}$ Prins, ${ }^{6}$ and Chang et al. ${ }^{7}$ This could be due to reduced placental circulation after the delivery of the first twin, breech deliveries, and potentially greater susceptibility of second twin to hypoxia. Higher rate perinatal mortality rate in second twin $(16.7 \%$ vs. $6.7 \%$ ) could be due to higher susceptibility of the second born twin to hypoxia, sepsis and respiratory distress. Similar higher perinatal mortality in second born twin was seen in other studies..$^{8-11}$

There was only slight increase in neonatal admission for the second twins $(30 \%$ vs. $25 \%)$. The major cause for admission in neonatal unit was prematurity for both the first twins $(\mathrm{n}=13)$ and the second twins $(n=12)$. This was followed by birth asphyxia (four second twins and one first twin). Similar finding was observed in the study done by Hanumaiah et $\mathrm{al}^{8}$ in India where very low birth weight was the leading cause for neonatal admission followed by respiratory distress and birth asphyxia.

The preterm second twins had lower Apgar scores $(p=0.049)$, which could be due to the reason that preterm babies are more easily affected by asphyxia than their term counterparts. Similar to this study, Dera et $\mathrm{al}^{12}$ and Armson et $\mathrm{al}^{13}$ also observed lower Apgar scores in premature neonates which they have attributed to the lower gestational age and low birth weight.

The second twin babies born preterm encountered higher rates of neonatal morbidities and mortalities compared to the twins born at term. Similar findings were seen in a study done by Crowther, ${ }^{11} \mathrm{Smith}$ et $\mathrm{al}^{14}$ and Hack et al. ${ }^{15}$

Dizygocity was more common in this study than monozygosity which was similar to the observations made by Lewi and Deprest, ${ }^{16}$ and Katz et al. ${ }^{17}$ In cases of monochorionicity, more of the second twins had Apgar score $<7$ than the first twin (MCDA: 6 vs. 4; MCMA: 6 vs. 3 ) similar to the study done by Shrim et al. ${ }^{18}$

Perinatal mortality rate in this study was similar to the study done by Hack et al, ${ }^{15}$ Wieczorek and Krasomski, ${ }^{19}$ Victoria et al, ${ }^{20}$ Sperling et $a l,{ }^{21}$ and Oldenburg et al. ${ }^{22}$

Vaginal delivery puts more stress on foetus resulting in lower Apgar score for the second twin $(\mathrm{p}<0.001)$. This could be explained by the fact that during the vaginal delivery, the second born twin is under stress of labour for a longer time than the first-born twin. Armson et $\mathrm{al}^{13}$ and Yang et al ${ }^{23}$ also observed low Apgar score for second twin who delivered vaginally. Similar to the study by Ginsberg et al, ${ }^{24}$ the Apgar score of the second twin was lower than the first twin in all the three cases of vaginal delivery of first twin and caesarean section for the second twin (one had zero score and two had 4-6). There was comparable low-Apgar score at 5 minutes in the twins who were delivered by caesarean section $(23.3 \%$ of the second twins and $20 \%$ of the first twins). Similar to this study, Bisschop et $\mathrm{al}^{25}$ did not observe any difference in the neonatal outcome of either twin at caesarean section.

Even when the second twin was delivered within half an hour of the birth of the first twin, the second twin had more chance of having Apgar score $<7$ than the first twin $(p=0.007)$. This can be explained by the fact that long inter-delivery interval in between the twins can lead to the foetal hypoxia due to diminished placental perfusion. ${ }^{26}$ There were less number of cases $(n=5)$ with $\geq 30$ minutes of inter-delivery interval to compare the Apgar scores.

Three first twins and two second twins with $\geq 30$ minutes inter delivery interval had early neonatal deaths. With regard to stillbirths two second twins and one first twin had inter-delivery interval of $<30$ minutes. Similar to this finding, in study done by Ezechi et $a l,{ }^{27}$ neonatal death were higher than still birth rates in retained second twin (47.3\% vs. $41.9 \%)$.

There was no correlation between neonatal admission and inter-delivery interval. In a study done by Healy and Gaddipati, ${ }^{28}$ there was not increased neonatal intensive admission even when the inter-delivery interval increased to $>30$ minutes.

Birth weight discordance between the twin pairs 
was calculated (in percentage) using the formula "birth weight of larger twin minus birth weight of the smaller twin and divided by the birth weight of the larger twin and finally multiplied by hundred". When the birth weight discordance was considered, in $<30 \%$ sub group, the second twins had more chance of having Apgar score of $<7 \quad(p=0.014)$. There was less number of cases $(n=8)$ with $\geq 30 \%$ birth weight discordance to compare the Apgar scores. Sujuki et $\mathrm{al}^{29}$ found that the smaller twin (usually the second twin $^{1,3}$ ) among the discordant twin pair had higher risk of lesser Apgar score at birth and umbilical artery $\mathrm{pH}$ of $<7.1$.

All stillbirths and $71 \%$ of early neonatal deaths had birth weight discordance of $<30 \%$ among perinatal deaths and similar result was reported by Garite et al. ${ }^{30}$ It can be explained by the fact that the birth weight discordance is not an independent factor leading to the adverse perinatal outcome in twin pregnancy. ${ }^{29}$ Some studies have shown birth weight discordance to be associated with increased mortality in the smaller second twin because of the twin to twin transfusion, which was not seen in this study. ${ }^{31,32}$

In those women who had twins with birth weight discordance of $<30 \%$, there was not increased chance of the second twin being admitted to neonatal intensive care unit. In the study done by Mazhar and Kanwal, ${ }^{33}$ higher percentage (16\% and $12.5 \%$ ) of twins needed admission only to the intermediate care baby unit in birth weight discordant pair than concordant pair $(7.8 \%$ and $7 \%)$.

Overall in this study, major differences between the first twin and the second twin could not be proven statistically. The much favorable outcome for both the first and the second born twin in this study may be due to the small group of patients, appropriate and timely antenatal diagnosis of twins, careful intrapartum monitoring of both foetuses; and majority of the women included in the study had uncomplicated ante-partum as well as intra-partum period and half of them had undergone caesarean section.

Although the second twin is more prone to birth asphyxia as a result of the prolong inter-delivery interval, umbilical cord prolapse, early placental separation, impaired placental perfusion, abnormal presentation and increased operative vaginal delivery which leads to much higher perinatal mortality in the second twin, many of these factors were not seen in this study which may be due to the increased operative mode of delivery.

\section{CONCLUSIONS}

The Apgar score of the second twins were lower than the first ones but the perinatal mortality among them were only slightly different. Neonatal intensive care unit admission rates were similar. The second born twins were likely to have lesser Apgar score $(<7)$ in preterm, dichorionic-diamniotic placentation, vaginal delivery, inter-delivery interval of $<30$ minutes and birth weight discordance of $<30 \%$. Further study with a bigger sample is required to describe more on the foeto-maternal parameters of twins.

\section{DISCLOSURE}

The authors report no conflicts of interest in this work. No violation of human rights and safety.

Funding: Nil

\section{REFERENCES}

1. Neilson JP, Barjoria R. Multiple pregnancy. In: Chamberlain G, Steer PJ, editors. Turnbull's obstetrics. 3rd ed. London: Churchill Livingstone; 2001. p. 229-46.

2. ACOG. Multiple gestation: complicated twin, triplet, and high-order multifetal pregnancy. Practice bulletin No.56. Obestet Gynaecol. 2004;104(4):869-83.

3. Multiple pregnancy. In:Cunningham FG, Levono KJ, Bloom SL, Hauth JC, Rouse DJ, Spong YC, editors. Williams obstetrics. 23rd ed. New York: Mc Graw Hill; 2010. p. 85989.

4. Paropakar Maternity and Women's Hospital. Smarika. 2012;53:56-7.

5. Hartley RS, Hitti J. Birth order and delivery interval: analysis of twin pair perinatal outcomes. J Matern Fetal Neonatal Med. 2005;17(6):375-80
6. Prins RP. The second-born twin: can we improve outcomes? Am J Obstet Gynecol. 1994;170(6):1649-56.

7. Chang TH, Jeng CJ, Lan CC. The effect of birth order in twins on fetal umbilical blood gas and Apgar score. Zhonghua Yi Xue Za Zhi. 1990;46(3):156-60.

8. Hanumaiah I, Shivanand DR, Visweshwaraiah KG, Hoolageri MS. Perinatal outcome of twin pregnancies at a tertiary care centre, South India. Int J Biol Med Res. 2013;4(1):2683-5.

9. Krajewski P, Kwiatkowska M, Kalinka J, Chudzika PM. Adaptation period of the first and second twin- comparative analysis of somatometric, biochemical, and clinical parameters. Arch Perinat Med. 2008;14(4):28-32.

10. Usta IM, Nassar AH, Awwad JT, Nakad TI, Khalil AM, Karam KS. Comparison of the perinatal morbidity and mortality of the presenting first twinnd its co-twin. J Perinatol. 2002;22(5):391-6. 
11. Crowther CA. Perinatal mortality in twin pregnancy. S Air Med J.1987;71:73-4.

12. Dera A, Grzegorz H, Breborowicz LK. The mode of delivery in twin pregnancy - part I: neonatal outcome. Arch Perinat Med. 2008;14(1):7-22.

13. Armson BA, O’Connell C, Persad V, Joseph KS, Young DC, Baskett TF. Determinants of perinatal mortality and serious neonatal morbidity in the second twin. Obstet Gynecol. 2006;108(3):556-64.

14. Smith GCS, Fleming KM, White IR. Birth order of twins and risk of perinatal death related to delivery in England, Northern Ireland, and Wales, 1994-2003: retrospective cohort study. BMJ. 2007;334(7593):576.

15. Hack KEA, Derks JB, Elias SG, Franx A, Roos EJ, Voerman $\mathrm{SK}$ et al. Increased perinatal mortality and morbidity in monochorionic versus dichorionic twin pregnancies: clinical implications of a large Dutch cohort study. BJOG 2008;115(1):58-67.

16. Lewi L, Deprest J. Fetal Problems in Multiple Pregnancy. In: James DK, Steer PJ, Weiner CP, Gonik B, editors. High risk pregnancy management options. 3rd ed. St. Louis: Elsevier; 2006. p. 524-60

17. Katz J, West KP, Khatry SK, Le Clerq SC, Christian P, Pradhan EK et al. Twinning rates and survival of twins in rural Nepal. Int J Epidemiol. 2001;30(4):802-7.

18. Shrim A, Weisz B, Gindes L, Gagnon R. Parameters associated with outcome in third trimester monochorionic diamniotic twin pregnancies. J Obstet Gynaecol Can. 2010;32(5):429-34

19. Wieczorek A, Krasomski G. Perinatal outcome in monochorionic versus dichorionic twin pregnancies. Ultrasound Obstet Gynecol. 2012;40(S1):225.

20. Victoria A, Mora G, Arias F. Perinatal outcome, placental pathology, and severity of discordance in monochorionic and dichorionic twins. Obstet Gynecol. 2001;97(2):310-5.

21. Sperling L, Kiil C, Larsen LU, Qvist I, Schwartz M, Jorgensen $\mathrm{C}$ et al. Naturally conceived twins with monochorionic placentation have the highest risk of fetal loss. Ultrasound Obstet Gynecol. 2006;28(5):644-52.

22. Oldenburg A, Rode L, Bodker B, Ersbak V, Holmskov A, Jorgensen FS et al. Influence of chorionicity on perinatal outcome in a large cohort of Danish twin pregnancies.
Ultrasound Obstet Gynecol. 2012;39(1):69-74

23. Yang Q, Wen SW, Chen Y, Krewski D, Fung K, Walker M. Neonatal death and morbidity in vertex-nonvertex second twins according to mode of delivery and birth weight. Am J Obstet Gynecol. 2005;192(3):840-7.

24. Ginsberg N, Levine EM. Delivery of the second twin. Int J Gynaecol Obstet. 2005;91(3):217-20.

25. Steins Bisschop CN, Vogelvang TE, May AM, Schuitemaker NW. Mode of delivery in non-cephalic presenting twins. Arch Gynecol Obstet . 2012;286(1):237-47.

26. Dera A. Twin pregnancy-physiology, complications and the mode of delivery. Archrives Perinat Med. 2007;13(3):7-16.

27. Ezechi OC, Fasubaa OB, Kalu BEK. Retained second twin: experience from Ile-Ife, Nigeria. East Afr Med J. 2003;80(2):110-3.

28. Healy AJ, Gaddipati S. Intrapartum management of twins: truths and controversies. Clin Perinatol. 2005;32(2):455-73.

29. Suzuki S, Elmer P, Inde Y, Hiraizumi Y, Miyake H. Growth discordance is not an independent risk factor for adverse perinatal outcomes in twin pregnancies. J Clin Gynecol Obstet. 2012;1:31-5.

30. Garite TJ, Clark RH, Elliott JP, Thorp J. Twins and triplets: the effect of plurality and growth on neonatal outcome compared with singleton infants. Am J Obstet Gynecol. 2004;191(3):700-7.

31. Breathnach FM, McAuliffe FM, Geary M, Daly S, Higgins JR, Dornan J et al. Definition of intersecond twinirth weight discordance. Obstet Gynecol. 2011;118(1):94-103.

32. Blickstein I. Managing multiple pregnancy and birth. In: Studd J, Tan LS, Chervenak FA, editors. Progress in obstetrics and gynecology. Vol 18. London: Elsevier; 2008. p. 111-24.

33. Mazhar SB, Kanwal S. Second twin birth weight discordance: associated factors and outcome. J Coll Physicians Surg Pak. 2010;20(6):391-4 